\title{
Complementary and Alternative Medicine Use among Patients with Chronic Tinnitus
}

\author{
Sumbule Koksoy Vayisoglu ${ }^{1 *}$ and Harun Gur ${ }^{2}$ \\ ${ }^{1}$ Department of Public Health Nursing, Nursing Faculty, Mersin University, Turkey \\ ${ }^{2}$ Department of Otorhinolaryngology, Medical School, Mersin University, Turkey \\ *Corresponding author: Sumbule Koksoy Vayisoglu, Department of Public Health Nursing, Nursing Faculty, Mersin \\ University, Mersin, Turkey, Tel: +90-324-241-00-00, GSM: +90-507-5050711
}

\begin{abstract}
Objective: There has been a marked increase in the use of complementary and alternative medicine (CAM) in recent years. The purpose of this study to assess that using of CAM methods in chronic tinnitus patients.

Material and method: The study was performed to chronic tinnitus patients by giving answers to a questionnaire with a face-to-face interview method. The questionnaire included questions about the socio-demographic features and CAM usage features. A total of 102 chronic tinnitus patients were evaluated in the study. The results were compared with the "chi-square test".
\end{abstract}

Results: A $11.8 \%$ of respondents were detected to be using at least one of the CAM method. The most commonly used CAM therapies were herbal products (10 patient), and second was acupuncture. There were no differences according to age, sex, hearing level, tinnitus duration, and educational level between CAM users and non-users. According to income levels rate of equivalent to income level patients was higher than expense and low income levels $(83.3 \%$ vs. $16.6 \%)$. The majority of information sources of respondents were media devices.

Conclusion: The use of CAM therapies by patients with chronic tinnitus was relatively low. Patients mostly used herbal products. Studies with larger participation are needed on this subject.

\section{Keywords}

Complementary, Alternative, Medicine, Tinnitus, Chronic

\section{Introduction}

Tinnitus is defined as a sound sensation that occurs in the absence of any acoustical stimulus. If tinnitus symptoms have persisted for more than six months, it is described as chronic tinnitus. Tinnitus as a public health problem has been reported in approximately 10 to $25 \%$ in the general population and in 1 to $2 \%$, tinnitus is severe enough to impair daily life significantly $[1,2]$. Although it is a common condition, patients may turn to complementary and alternative medicine (CAM) when medical treatment cannot be relieved due to the lack of effective pharmacological treatment $[3,4]$.

According to National Center for Complementary and Alternative Medicine (NCCAM), CAM therapies are a group of diverse medical and health care practices and products that are not generally considered to be part of conventional medicine. According to this definition CAM therapies can be divided into five main categories as biologically based practices, energy medicine, manipulative and body-based practices, mind-body medicine, and whole medical systems [5]. There is growing interest in use of CAM among the general population. Rates of CAM use vary widely in the literature from $6 \%$ to $84 \%$, and broadly show that patients with a chronic condition are more likely to use CAM than the general population [6-9]. Although tinnitus is a chronic disease but CAM usage among tinnitus patients is not well defined in the literature.

Due to the increase in the use of CAM therapies in the community, the knowledge of CAM therapies used by patients appears to be an important factor in patient management of public health nursing practice. In this paper, we investigate the prevalence of CAM use among patients with chronic tinnitus. The extent to which CAM and pharmaceutical medications are used in

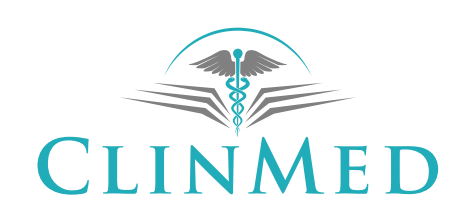

INTERNATIONAL LIBRARY
Citation: Vayisoglu SK, Gur H (2020) Complementary and Alternative Medicine Use among Patients with Chronic Tinnitus. Int Arch Nurs Health Care 6:146. doi.org/10.23937/2469-5823/1510146 Accepted: September 28, 2020: Published: September 30, 2020

Copyright: (C) 2020 Vayisoglu SK, et al. This is an open-access article distributed under the terms of the Creative Commons Attribution License, which permits unrestricted use, distribution, and reproduction in any medium, provided the original author and source are credited. 
dependently or in combination to treat this condition; and the sociodemographic characteristics of those who use CAM in relation to this disorder, and compare them with those who do not.

\section{Material \& Method}

This destructive study enrolled total 102 patients with chronic tinnitus between January-June 2018. All patients included in this study were suffering from chronic subjective tinnitus were 18 years or older. Haphazard sampling method as a non-probability samples method was used for patients' election. This study was conducted with the patients who applied to the otorhinolaryngology polyclinic with the complaint of chronic tinnitus in the first 6 months, met the inclusion criteria and accepted to participate in the study. Only patients with chronic tinnitus without comorbidities such as diabetes mellitus, chronic kidney failure, or chronic lung disease were included in the study. Patients under 18 years of age and patients with comorbid diseases were excluded from the study. This study was approved by Research Ethics Committee of Mersin University.

A face-to-face interview was conducted using a structured questionnaire. The questionnaire was designed in the light of literature and the question samples seen in Table 1 and Table 2 [10-12]. A written informed consent for participation in the study was obtained from participants. Each patient was interviewed for 8 to 10 minutes by the same interviewer in the clinic examination room either before or after routine follow-up visit. Demographic information (age, gender, education level, marital status, and health insurance) was recorded for each patient. When respondents were asked about the pharmaceutical medications that they may have used for tinnitus they were specifically instructed not to include vitamin and mineral supplements as well as natural or herbal medications. Thus, any prescribed vitamin and mineral supplements are not included in the CAM count. Data were evaluated by SPSS software (ver. 16) using descriptive statistics such as number, percentage, and arithmetic mean and chi-square test for significance. The $p \leq 0.05$ was considered as statistically significant.

\section{Results}

This study enrolled a total 102 patients and the age of participants ranged from 20 to 78 years, with a mean age of $54( \pm 12.5$ ) years ( $52 \%$ female, $48 \%$ male). Demographic features of the whole study population were summarised in detail in Table 1 and Table 2. According to education levels the participants divided to $10.8 \%$ non-literate, $50 \%$ first school, $25.5 \%$ high school and $13.7 \%$ license and post-graduate level. According to income levels, $56.9 \%$ equivalent to income $5.9 \%$ expense high income level and $37.3 \%$ low income level. Among patients $85.3 \%$ married and $14.7 \%$ single.

In patients using CAM $66.7 \%$ of the patients are female, $33.3 \%$ male. Although CAM usage higher in female patients this difference is not statistically significance. Also $66.7 \%$ primary school, $25 \%$ high school, $8.3 \%$ college graduates. $66.7 \%$ of the patients are married, $33.3 \%$ are single, $58.3 \%$ of them are equal to their income and $16.7 \%$ of them are less than their expenses. While $58.3 \%$ of the patients were using medication for tinnitus, $41.7 \%$ did not during CAM usage (Table 3 ).

Twenty of 102 patients $(11.8 \%)$ received CAM. There were no differences according to age, sex, hearing level, tinnitus duration, and educational level between CAM

Table 1: Sociodemographic features of tinnitus patients $(n=102)$.

\begin{tabular}{|c|c|c|c|}
\hline & & $\mathbf{n}$ & $\%$ \\
\hline \multirow[t]{2}{*}{ Gender } & Female & 53 & 52.0 \\
\hline & Male & 49 & 48.0 \\
\hline \multirow[t]{4}{*}{ Education levels } & Non-literate & 11 & 10.8 \\
\hline & First school & 51 & 50.0 \\
\hline & High school & 26 & 25.5 \\
\hline & License and postgraduate & 14 & 13.7 \\
\hline \multirow[t]{2}{*}{ Marital status } & Maried & 87 & 85.3 \\
\hline & Single & 15 & 14.7 \\
\hline \multirow[t]{3}{*}{ Income levels } & Equivalent to income & 58 & 56.9 \\
\hline & Expense high income & 6 & 5.9 \\
\hline & Low income & 38 & 37.3 \\
\hline \multirow[t]{2}{*}{ Tinnitus duration } & Less than one year & 22 & 21.6 \\
\hline & More than one year & 80 & 78.4 \\
\hline \multirow[t]{2}{*}{ Medication for tinnitus } & Yes & 44 & 43.1 \\
\hline & No & 58 & 56.9 \\
\hline \multirow[t]{2}{*}{ CAM usage } & Yes & 12 & 11.8 \\
\hline & No & 90 & 88.2 \\
\hline
\end{tabular}


Table 2: Characteristics of tinnitus patients regarding to CAM usage.

\begin{tabular}{|c|c|c|c|}
\hline & & $\mathbf{n}$ & $\%$ \\
\hline \multirow[t]{2}{*}{ CAM usage } & Using & 12 & 11.8 \\
\hline & Not using & 90 & 88.2 \\
\hline \multirow[t]{2}{*}{ Used CAM therapies } & Herbal products & 10 & 83.3 \\
\hline & Acupuncture & 2 & 16.6 \\
\hline \multirow[t]{2}{*}{ What is effective in choosing a method? } & Media & 10 & 83.3 \\
\hline & Social environment & 2 & 16.6 \\
\hline \multirow[t]{2}{*}{ Use with medical treatment } & Yes & 8 & 7.8 \\
\hline & No & 4 & 3.9 \\
\hline \multirow[t]{2}{*}{ State of informing the doctor/nurse about the using CAM } & Yes & 0 & 0 \\
\hline & No & 12 & 100 \\
\hline \multirow[t]{2}{*}{ Thinking that the used method would harm } & Its harmful & 2 & 16.6 \\
\hline & İts harmless & 10 & 83.3 \\
\hline \multirow[t]{2}{*}{ Would you recommend the method you use to the patients around you? } & Yes & 0 & 0 \\
\hline & No & 12 & 100 \\
\hline \multirow[t]{2}{*}{ Did you benefit from the method you used? } & Yes & 0 & 0 \\
\hline & No & 12 & 100 \\
\hline \multirow[t]{2}{*}{ CAM usage reason } & Medical treatment did not treat & 10 & 83.3 \\
\hline & Despair & 2 & 16.6 \\
\hline
\end{tabular}

Table 3: Statistical evaluation of the patients with and without CAM usage.

\begin{tabular}{|c|c|c|c|c|c|c|c|c|}
\hline & & \multicolumn{4}{|c|}{ CAM Usage } & & & \multirow[b]{3}{*}{$p$} \\
\hline & & \multicolumn{2}{|c|}{ Used } & \multicolumn{2}{|c|}{ Not used } & \multicolumn{2}{|c|}{ Total } & \\
\hline & & n & $\%$ & n & $\%$ & $\mathbf{n}$ & $\%$ & \\
\hline \multirow{4}{*}{ Years } & $20-34$ & 1 & 8.3 & 5 & 5.6 & 6 & 5.9 & \multirow[t]{4}{*}{0.470} \\
\hline & $35-49$ & 2 & 16.7 & 24 & 26.7 & 26 & 25.5 & \\
\hline & $50-64$ & 8 & 66.7 & 41 & 45.6 & 49 & 48.0 & \\
\hline & 65 and older & 1 & 8.3 & 20 & 22.2 & 21 & 20.6 & \\
\hline \multirow[t]{2}{*}{ Gender } & Female & 8 & 66.7 & 45 & 50.0 & 53 & 52.0 & \multirow[t]{2}{*}{0.278} \\
\hline & Male & 4 & 33.3 & 45 & 50.0 & 49 & 48.0 & \\
\hline \multirow[t]{4}{*}{ Education levels } & Non-literate & 0 & 0 & 11 & 12.2 & 11 & 10.8 & \multirow[t]{4}{*}{0.473} \\
\hline & First school & 8 & 66.7 & 43 & 47.8 & 51 & 50.0 & \\
\hline & High school & 3 & 25.0 & 23 & 25.6 & 26 & 25.5 & \\
\hline & License and postgraduate & 1 & 8.3 & 13 & 14.4 & 14 & 13.7 & \\
\hline \multirow[t]{2}{*}{ Marital status } & Married & 8 & 66.7 & 79 & 87.8 & 87 & 85.3 & \multirow[t]{2}{*}{0.052} \\
\hline & Single & 4 & 33.3 & 11 & 12.2 & 15 & 14.7 & \\
\hline \multirow[t]{3}{*}{ Income levels } & Equivalent to income & 10 & 83.3 & 48 & 53.3 & 58 & 56.9 & \multirow[t]{3}{*}{0.134} \\
\hline & Expense high income & 0 & 0 & 6 & 6.7 & 6 & 5.9 & \\
\hline & Low income & 2 & 16.6 & 36 & 40.0 & 38 & 37.3 & \\
\hline \multirow[t]{2}{*}{ Tinnitus duration } & Less than one year & 7 & 58.3 & 37 & 41.1 & 44 & 43.1 & \multirow[t]{2}{*}{0.258} \\
\hline & More than one year & 5 & 41.7 & 53 & 58.9 & 58 & 56.9 & \\
\hline \multirow{2}{*}{$\begin{array}{l}\text { Medication for tinnitus } \\
\text { during CAM usage }\end{array}$} & Yes & 3 & 25.0 & 19 & 21.1 & 22 & 21.6 & \multirow[t]{2}{*}{0.758} \\
\hline & No & 9 & 75.0 & 71 & 78.9 & 80 & 78.4 & \\
\hline
\end{tabular}

users and non-users. According to income levels rate of equivalent to income level patients was higher than expense and low income levels ( $83.3 \%$ vs. 16.6\%). Comparison of demographic features between CAM users and non-users were summarised in Table 3. Patients using CAM were generally informed by media devices or their social circle about CAM. Ten patients informed by internet and two patients by social circle.

Majority of CAM used by the patients were herbal products (83.3\%, 10 of 12 patients). Six of the patients received CAM through outer ear canal route (Hypericum perforatum oil, Ecballium elaterium, cabbage juice, on- 
ion juice). Four patients used a herbal product through oral route (herbal tea). Two patients used acupuncture.

We look at the use of reason, 10 patients (83.3\%) used CAM with thought of medical treatment did not benefit and 2 patients (16.6\%) received CAM due to hopelessness and despair. All patients used CAM though the CAM would not be harmful. All of the patients used CAM $(100 \%)$ did not experience any beneficial effect of CAM. Also they said they would not propose CAM usage for tinnitus because of there is not any benefit. Furthermore there is some harmful effect found due to used CAM therapies. One patient had tympanic membrane perforation due to Ecballium elaterium oil usage through ear canal. Two patients have nausea and stomach pain due to herbal products through oral route.

All CAM used patients (100\%) did not inform their clinicians while using CAM. Also all CAM used patients have no opinion or knowledge about effects or knowledge about side effects of the CAM.

All CAM used patients discontinued CAM. Three patients discontinued CAM due to warnings about side effects of CAM. Nine patients discontinued CAM due to it's not any beneficial effects.

According to tinnitus duration of the patients with tinnitus $21.6 \%$ for less than one year, $25.5 \%$ for one to two years, $33.3 \%$ for $3-9$ years and $19.6 \%$ for more than 10 years has tinnitus. Seven of 12 CAM used patients had tinnitus less than one year and five patients had more than one year. There is not statistically significant difference according to tinnitus duration (Table 3 ).

\section{Discussion}

Previous studies reported that the reasons for patients with chronic diseases to choose such CAM therapies may be related to the fact that their diseases are a chronic, devastating or incurable with conventional treatment modalities. CAM usage is well defined in some chronic diseases such as diabetes mellitus, hypertension, arthritis or cancer, but limited data has been found among chronic tinnitus patients in the literature [13-15]. This is the first study for CAM use among patients with chronic tinnitus.

Although many people learn to live with tinnitus, some find it severely debilitating. In the absence of relief by medical treatment, the patients are may be turning to CAM $[2,16,17]$. In our study CAM usage prevalence is $11.8 \%$ in patients with tinnitus. There is no study in the literature about the use of CAM in tinnitus patients. Therefore, we do not have a chance to compare with other studies. However, a low rate was obtained from the studies on the use of CAM in other chronic diseases. CAM usage estimates from other studies vary widely (34 to 90\%) due to differences in determining CAM use, including multivitamins, minerals, or prayer, different populations or geographical differences $[8,13,18]$. Our low rates of CAM usage may be due to small number of participants. Also, in our study, we did not accept the use of vitamins as CAM therapies because some vitamin supplements are also used as a part of medical treatment in tinnitus patients [1].

Nonconventional treatment modalities have increased in prevalence among both patients with chronic tinnitus. However there is no evidence that such methods have reduced tinnitus or associated stress in the literature. Many of these approaches have been shown to benefit some tinnitus sufferers, but none have shown efficacy in the majority of tinnitus patients $[2,3,19]$. CAM is defined by the NCCAM as a group of diverse medical and healthcare systems, practices, and products that are not normally considered to be conventional medicine. Included in this type of therapy are various modalities such as herbal products, acupuncture, chiropractic, and massage, among others. It's reported that use of these therapies is common in the general population [20].

It was observed in our study that only two CAM methods were used as herbal products (10 patients) and acupuncture (two patients). In our study, the main types of CAM used were herbal products similar to other CAM used patients with chronic diseases. It is not surprising, because most patients with chronic diseases may have positive opinions about CAM due to its organic nature and easily availability of CAM $[15,21]$. Healthcare professionals should be aware of any CAM use for patients due to possible adverse side effects and communication with other drugs. Some products such as Ginkgo biloba and ginseng have an antiplatelet effect and can cause bleeding problems. Also some herbal products can cause serious consequences such as liver failure, kidney failure, and death, so they should not be taken or only taken under the supervision of a healthcare professional $[15,21]$.

Although herbal products are generally used orally, but in our study, it was observed that they were mostly used through the external auditory canal. This situation arises from the fact that tinnitus complaint originates from the ear. The risk of ontological complications such as external otitis or tympanic membrane perforation is higher due to the herbal products used in the external auditory canal. In our study, tympanic membrane perforation occurred in one of 8 patients using herbal products from the external auditory canal.

Acupuncture is presumably the most widely recognized CAM therapies and is an integral part of traditional Chinese medicine practice. There are some studies on the effectiveness of acupuncture in treating chronic tinnitus, but no studies have been found to be effective. However, there are many anecdotal reports and small case series showing significant improvement in upto $40 \%$ of patients [16-18]. In our study two patients used acupuncture but they not any improvement for tinnitus. 
In our study the most common sources of CAM information were recommendation from media and social circles such as friends and families similar to the literature $[6,7]$. Older female patients with higher levels of education and higher income levels were more likely to be CAM users in some studies $[9,10]$. However, some studies have not confirmed this higher prevalence in women or in patients with higher education similarly our results. Also, the present study found no significant relationship in CAM usage and gender, age, education level, or income levels. This could be because the studied population was low.

Despite its wide spread use, the use of CAM is not widely documented in the medical records of patients because these patients may not tell their CAM use to healthcare professionals. Numerous studies have found that upto 90 percent of patients with cancer use a CAM for at least some of their treatment within a year. However, patients may not explain the use of CAM unless specifically requested $[6,9]$. In our study none of the patients using CAM did not inform the healthcare professionals about the used CAM. Therefore public health nurses should know common used CAM therapies in their region and the use of CAM therapies should be particularly questioned.

As a conclusion the use of CAM by patients with chronic tinnitus was relatively low. Patients mostly used herbal products. Studies with larger participation are needed on this subject.

\section{Limitation of the Study}

This study is limited with patients who admitted to the otorhinolaryngology polyclinics at the one center.

\section{Conflict of Interest}

There is no conflict of interest or financial disclosure.

\section{References}

1. Tunkel DE, Bauer CA, Sun GH, Rosenfeld RM, Chandrasekhar SS, et al. (2014) Clinical practice guideline: Tinnitus. Otolaryngol Head Neck Surg 151: S1-S40.

2. Koksoy S, Eti CM, Karataş M, Vayisoglu Y (2018) The effects of yoga in patients suffering from subjective tinnitus. Int Arch Otorhinolaryngol 22: 9-13.

3. Wolever RQ, Price R, Hazelton AG, Dmitrieva NO, Bechard $E M$, et al. (2015) Complementary therapies for significant dysfunction from tinnitus: Treatment review and potential for Integrative medicine. Evid Based Complement Alternat Med 2015: 931418.

4. Roland LT, Lenze EJ, Hardin FM, Kallogjeri D, Nicklaus J, et al. (2015) Effects of mindfulness based stress reduction therapy on subjective bother and neural connectivity in chronic tinnitus. Otolaryngol Head Neck Surg 152: 919-926.

5. Trail-Mahan T, Mao CL, Bawel-Brinkley K (2013) Complementary and alternative medicine: Nurses' attitudes and knowledge. Pain Manag Nurs 14: 277-286.

6. Kessel KA, Lettner S, Kessel C, Bier H, Biedermann T, et al. (2016) Use of Complementary and Alternative Medicine
(CAM) as part of the oncological treatment: Survey about patients' attitude towards CAM in a University-Based Oncology Center in Germany. PLoS One 11: e0165801.

7. Mbizo J, Okafor A, Sutton MA, Leyva B, Stone LM, et al. (2018) Complementary and alternative medicine use among persons with multiple chronic conditions: Results from the 2012 National Health Interview Survey. BMC Complement Altern Med 18: 281.

8. Oyunchimeg B, Hwang JH, Ahmed M, Choi S, Han D (2017) Complementary and alternative medicine use among patients with cancer in Mongolia: A National hospital survey. BMC Complement Altern Med 17: 58.

9. Smith CA, Hunter J, Delaney GP, Ussher JM, Templeman $\mathrm{K}$, et al. (2018) Integrative oncology and complementary medicine cancer services in Australia: Findings from a national cross-sectional survey. BMC Complement Altern Med 18: 289.

10. Köksoy S, Akan N, Erdoğan S, Karatas B (2013) Knowing and using complementary and alternative therapies of the doctors, nurses and midwives who working in inpatient health institutions. Mersin University Medical Journal 14: 1725.

11. Metcalfe A, Williams J, McChesney J, Patten SB, Jette N (2010) Use of complementary and alternative medicine by those with a chronic disease and the general population-results of a national population based survey. BMC Complement Altern Med 10: 58.

12. Armstrong RA, Thiébaut PS, Brown JL, Nepal B (2011) Australian adults use complementary and alternative medicine in the treatment of chronic illness: A national study. Aust N Z J Public Health 35: 384-390.

13. Miller MC, Pribitkin EA, Difabio T, Keane WM (2010) Prevalence of complementary and alternative medicine use among a population of head and neck cancer patients: A survey-based study. Ear Nose Throat J 89: E23-E27.

14. Shakeel M, Trinidade A, Jehan S, Ah-See KW (2010) The use of complementary and alternative medicine by patients attending a general otolaryngology clinic: Can we afford to ignore it? Am J Otolaryngol 31: 252-260.

15. Mongiovi J, Shi Z, Greenlee H (2016) Complementary and alternative medicine use and absenteeism among individuals with chronic disease. BMC Complement Altern Med 16: 248.

16. Pang $P$, Shi $Y, X u H$, Deng L, Wu S, et al. (2019) Acupuncture methods put to the test for a tinnitus study: A Bayesian analysis. Complement Ther Med 42: 205-213.

17. Kuzucu I, Karaca O (2020) Acupuncture treatment in patients with chronic subjective tinnitus: A prospective, randomized study. Med Acupunct 32: 24-28.

18. Linde K, Vickers A, Hondras M, Riet GT, Thormählen J, et al. (2001) Systematic reviews of complementary therapies - an annotated bibliography. Part 1: Acupuncture. BMC Complement Altern Med 1: 3.

19. Asher BF, Seidman M, Snyderman C (2001) Complementary and alternative medicine in otolaryngology. Laryngoscope 111: 1383-1389.

20. Kramlich D (2014) Introduction to complementary, alternative, and traditional therapies. Crit Care Nurse 34: 50-56.

21. Werneke U, Earl J, Seydel C, Horn O, Crichton P, et al. (2004) Potential health risks of complementary alternative medicines in cancer patients. $\mathrm{Br} \mathrm{J}$ Cancer 90: 408-413. 